\title{
Reduction of ATPase activity accompanied by photodecomposition of ergosterol by near-UV irradiation in plasma membranes prepared from Saccharomyces cerevisiae
}

\author{
Shin-ichiro Arami, ${ }^{1}$ Megumi Hada ${ }^{2}$ and Mikiro Tada ${ }^{1}$ \\ Author for correspondence: Shin-ichiro Arami. Tel: +81862518310 . Fax: +81862540714 \\ e-mail: baiyou-1@cc.okayama-u.ac.jp
}

1 Division of Biological Function and Genetic Resources Science, Faculty of Agriculture, Okayama University, Tsushima-naka, Okayama, 700, Japan

2 Department of Biology, Kobe University, Rokkodai, Nada-ku, 657 Kobe, Japan

\begin{abstract}
When plasma membranes prepared from the yeast Saccharomyces cerevisiae were exposed to near-UV radiation, photodecomposition of ergosterol and reduction of ATPase activity occurred simultaneously. The $V_{\max }$ for ATPase activity decreased markedly with increasing near-UV dosage while the $K_{m}$ value remained constant. When ATPase solubilized from the plasma membrane was exposed to near-UV, the activity remained constant irrespective of dosage, indicating that the ATPase molecule itself was not damaged by near-UV irradiation. The relationship between content of ergosterol and ATPase activity was examined using liposomes constructed with lipids extracted from the membrane. Maximum activity of ATPase was seen at $5 \%$ ergosterol in liposomes; this activity was 2.5 times greater than that in liposomes without ergosterol. Activity of ATPase bound to liposomes with $5 \%$ ergosterol was reduced after near-UV irradiation, while the activity remained unchanged in the case of the liposomes without ergosterol. Fluidity of the liposomes with $5 \%$ ergosterol also decreased with increasing near-UV dosage.

Dosage-response curves for reduction of ATPase activity and for decrease in fluidity were similar to that for photodecomposition of ergosterol. These results suggested that the reduction of ATPase activity in the membrane by near-UV irradiation was not caused by photochemical degradation of the primary structure of the ATPase molecule, but was attributable to conformational change resulting from an alteration in the higher-order structure of the membrane due to photochemical decomposition of ergosterol.
\end{abstract}

Keywords: near-UV, ergosterol, Saccharomyces cerevisiae, ATPase, plasma membrane

\section{INTRODUCTION}

Near-UV irradiation reduces various functions of the plasma membrane and finally results in inactivation of the cell. However, the initial photochemical reactions and molecular mechanisms for these phenomena are little understood. We reported previously that ergosterol, which is one of the major components in the yeast plasma membrane, was photochemically decomposed (Arami et al., 1997) and that cell survival and membrane functions such as the permeability barrier and active transport were sigmoidally decreased by increasing doses of near-UV irradiation in Saccharomyces cerevisiae (Arami et al., 1993).

Ergosterol plays an important role in the normal physiological function of the plasma membrane by regulating the delicate balance among other membrane components such as lipids and proteins. The fluid mosaic model (Singer \& Nicolson, 1972) effectively shows interaction among these components and is significant in examining the transition of membrane-bound enzymes involved in membrane function. The physiological activity of membrane-bound proteins, which are in contact with other components, is sensitive to structural changes or physicochemical properties of other membrane components. Therefore, slight changes in membrane components may cause breakdown of the delicate balance of the plasma membrane and eventually lead to a reduction of membrane function.

Different components of the plasma membrane play important roles in membrane function. As regards physicochemical properties of the membrane, the acyl 
chain type of phospholipids and the concentration of sterol compounds affect membrane permeability (Anderson \& Thompson, 1992; Corvera et al., 1992; In't Veld et al., 1992), and asymmetry of phospholipids induces change in electrical potential of the membrane surface (Cerbon \& Calderon, 1991). As to physiological function, peroxidation of lipids in the membrane reduces the activity of membrane-bound enzymes (Baba et al., 1981; Kukreja et al., 1988; Ohta et al., 1989; Scherer \& Deamer, 1986) and cation transport (Marshanskii et al., 1983), and the length and degree of unsaturation in acyl chains of lipids influence active transport (Drissen $e$ t al., 1988; In't Veld et al., 1991, 1992). Moreover, molecular species of lipids also affect ATPase activity in the membrane (Corvera et al., 1992; Kasamo \& Nouchi, 1987; Kasamo, 1990; Serrano et al., 1988). Like lipids, cholesterol also affects the activity of membrane-bound enzymes (George \& McElhaney, 1992). Thus membrane functions are closely regulated by various membrane components.

In this study, we investigated the relationship between change in ATPase activity and decomposition of ergosterol by near-UV irradiation using both intact yeast plasma membranes and reconstructed liposomes.

\section{METHODS}

Isolation of plasma membranes. Saccharomyces cerevisiae IS66-4C $\alpha$ was grown in the dark at $26^{\circ} \mathrm{C}$ in YPD medium (yeast extract $1 \%$, bactopeptone $2 \%$ and glucose $2 \%, \mathrm{w} / \mathrm{v}$ ) with continuous shaking at 125 r.p.m. for $20 \mathrm{~h}$, at which time the culture was approaching stationary phase. After harvest, the yeast cells were washed twice with distilled water. Plasma membranes were isolated as described previously (Arami et al., 1997). The yeast cells were suspended in $0 \cdot 1 \mathrm{M}$ Tris $/ \mathrm{HCl}$ buffer ( $\mathrm{pH} 7 \cdot 2$ ) containing $10 \mathrm{mM}$ EDTA, 1.2 M sorbitol and $1 \mathrm{mg}$ Zymolyase $\mathrm{ml}^{-1}$. The reaction mixture was incubated at $30^{\circ} \mathrm{C}$ for $2 \mathrm{~h}$ and protoplasts were formed. After washing twice with the same buffer lacking Zymolyase, protoplasts were burst by suspension in $0 \cdot 1 \mathrm{M}$ Tris/ $\mathrm{HCl}$ buffer $(\mathrm{pH} 7 \cdot 4)$. Impurities were removed by centrifugation at $2300 \mathrm{~g}$ for $5 \mathrm{~min}$ at $4{ }^{\circ} \mathrm{C}$. The microsomal fraction was precipitated by centrifugation at $12000 \mathrm{~g}$ for $30 \mathrm{~min}$ at $4^{\circ} \mathrm{C}$. After washing the precipitate twice with the latter buffer, the plasma membrane fraction was collected using a sucrose density gradient at $100000 \mathrm{~g}$ for $60 \mathrm{~min}$ at $4{ }^{\circ} \mathrm{C}$. The layer containing the plasma membranes was identified by assay of $\mathrm{Mg}^{2+}$-ATPase, which was used as a marker enzyme. This layer was not contaminated by mitochondria since the ATPase activity was not inhibited in the presence of sodium azide.

Lipid extraction and preparation of liposomes. The total lipids from the plasma membrane fraction of yeast cells were extracted utilizing established procedures (Allen \& Good, 1971) with slight modifications. The plasma membranes were suspended in chloroform/methanol $(1: 2, \mathrm{v} / \mathrm{v})$ and stirred vigorously. After centrifugation of the suspension at $1000 \mathrm{~g}$ for $5 \mathrm{~min}$, the residue was re-extracted with chloroform/ methanol $(1: 1, \mathrm{v} / \mathrm{v})$. A $0.5 \% \mathrm{NaCl}$ solution was added to the chloroform layer with vigorous stirring, and the chloroform layer was concentrated by using a rotary vacuum evaporator. Total lipids extracted were fractionated using Silica Gel C-100 column chromatography $(13 \times 2.0 \mathrm{~cm})$ in the order chloroform, acetone and methanol, separating neutral lipids con- taining ergosterol, glycolipids and phospholipids, respectively. Composition of the lipids separated was analysed by twodimensional TLC. For TLC, Silica Gel 60 plates were activated by heating at $120^{\circ} \mathrm{C}$ for $60 \mathrm{~min}$ and then cooled to room temperature. The plates were developed in the first dimension with chloroform/methanol/water $(65: 25: 4$, by vol.) and dried for $20 \mathrm{~min}$ under vacuum. The second solvent was chloroform/methanol/ammonia (65:35:5, by vol.). The lipids were identified by co-chromatography using lipid standards.

Reconstructed liposomes were produced as described by Darszon et al. (1980). The ATPase solubilized from the plasma membrane of the yeast cells was incorporated deep into the liposomes by sonication with a bath sonicator. The ATPase was solubilized from the plasma membrane by established procedures (Davis \& Hammes, 1989). Reconstructed liposomes were isolated by gel filtration with Sephadex G-100, using $10 \mathrm{mM}$ Tris $/ \mathrm{HCl}$ buffer $(\mathrm{pH} \mathrm{7.4}$ ) containing $1 \mathrm{mM}$ EDTA and $1 \mathrm{mM} \mathrm{ATP}$.

Irradiation procedure. A fluorescent lamp (National FL20S.BL-B) was used as the light source (intensity $14 \mathrm{~W} \mathrm{~m}^{-2}$, wavelength range $300-400 \mathrm{~nm}$ ). The plasma membrane was suspended in deionized distilled water to a final concentration of $0.5 \mathrm{mg}$ protein $\mathrm{ml}^{-1}$ and was exposed to near-UV radiation with continuous stirring and ice cooling as previously described (Arami et al., 1997). When nitrogen gas or air was bubbled through during irradiation, the yeast cells were suspended in water degassed by sonication under reduced pressure. The flow rate of gases was $70 \mathrm{ml} \mathrm{min}^{-1}$.

Assay of enzyme activity. ATPase activity was measured as described by Kasamo (1986) with slight modifications. The plasma membranes and reconstructed liposomes were suspended, to a final concentration of 1 and $0.2 \mathrm{mg}$ protein $\mathrm{ml}^{-1}$, respectively, in a reaction mixture containing $50 \mathrm{mM}$ Tris/ $\mathrm{HCl}(\mathrm{pH} \mathrm{7 \cdot 8)}, 3 \mathrm{mM} \mathrm{MgCl}$ and $2 \mathrm{mM} \mathrm{ATP}$. After incubation at $30^{\circ} \mathrm{C}$ for $10 \mathrm{~min}$, the phosphate released from ATP was determined by established procedures (Fiske \& Subbarow, 1925).

Activity of alkaline phosphatase was measured as described by Ito \& Ito (1983). The plasma membranes were suspended, to a final concentration of $1.25 \mathrm{mg}$ protein $\mathrm{ml}^{-1}$, in a reaction mixture containing $0.2 \mathrm{M}$ Tris $/ \mathrm{HCl}(\mathrm{pH} 8.5)$ and $10 \mathrm{mM} p$ nitrophenyl phosphate. After incubation at $30^{\circ} \mathrm{C}$ for $30 \mathrm{~min}$, $0.5 \mathrm{ml} 1 \mathrm{M} \mathrm{NaCO}_{3}$ was added to stop the reaction. The resultant $p$-nitrophenol was determined by measuring $A_{400}$.

For assay of invertase, the plasma membranes were suspended, to a final concentration of $1 \mathrm{mg}$ protein $\mathrm{ml}^{-1}$, in $0.2 \mathrm{M}$ acetate buffer (pH 5.2) containing $12.5 \mathrm{mM}$ sucrose, and incubated at $50{ }^{\circ} \mathrm{C}$ for $5 \mathrm{~h}$. The reaction was stopped by addition of $2 \mathrm{M}$ $\mathrm{NaOH}$ and the $\mathrm{pH}$ of this mixture was adjusted to $7 \cdot 0$. After filtration through a cellulose acetate filter (pore size $0.45 \mu \mathrm{m}$ ), glucose produced was determined with mutarotase-GOD assay kit (Wako Pure Chemical Industries). Concentration of protein was determined using the Bio-Rad protein assay kit.

Determination of membrane fluidity. A pyrene derivative, which was a fluorescent probe for the lipid bilayer, was used for determination of membrane fluidity (Kitagawa \& Takegaki, 1992). Pyrene dodecanoic acid was dissolved in THF (tetrahydrofuran) $1: 1, \mathrm{v} / \mathrm{v}$ ) to a final concentration of $0.35 \mathrm{mM}$ and added to a suspension of reconstructed liposomes. After the suspension had been incubated at $30^{\circ} \mathrm{C}$ for $20 \mathrm{~min}$ in the dark, it was excited at $340 \mathrm{~nm}$ and the fluorescence spectrum was measured at $350-550 \mathrm{~nm}$. 
Monomer and excimer peaks were detected at 397 and $464 \mathrm{~nm}$, respectively. Fluidity was represented by the ratio of fluorescence intensity of excimer to monomer. When the ratio of excimer to monomer was large, the fluidity was high.

Assay of the permeability barrier in liposomes. The permeability barrier of liposomes was measured as previously described (Braganza et al., 1983) with modifications. Liposomes were prepared by using $10 \mathrm{mM}$ Tris/HCl buffer ( $\mathrm{pH} 7 \cdot 0)$ containing phenol red $\left(5 \mathrm{mg} \mathrm{ml}^{-1}\right)$ instead of distilled water in the method described above. After liposomes containing phenol red had been exposed to near-UV radiation at $25^{\circ} \mathrm{C}$, they were collected by centrifugation at $10000 \mathrm{~g}$ for $30 \mathrm{~min}$. Then $50 \mathrm{mM} \mathrm{NaOH}$ solution was added to the supernatant and the $A_{550}$ was measured. When near-UV radiation induced damage in the permeability barrier of liposomes, phenol red leaked out, and the $A_{550}$ increased with increased $\mathrm{pH}$ of the supernatant.

Determination of ergosterol content. Ergosterol content was determined as described previously (Arnezeder et al., 1989) with slight modifications. Samples exposed to near-UV were refluxed for $1 \mathrm{~h}$ in $5 \mathrm{ml}$ of $90 \%(\mathrm{v} / \mathrm{v})$ ethanol containing 7 dehydrocholesterol as an internal standard. After addition of $5 \mathrm{ml}$ of $50 \%(\mathrm{v} / \mathrm{v})$ ethanol, the sample was filtered through a cellulose acetate filter (pore size $0.45 \mu \mathrm{m}$ ). The filtrate was treated with a SEP-PACK C-18 cartridge (Millipore) and ergosterol was dissolved with 2-propanol. The solution containing ergosterol was analysed with an HPLC apparatus attached to a Nucleosil ODS column $(4.5 \times 150 \mathrm{~mm} ; 5 \mu \mathrm{m}$ particles; Chemco Scientific). Using methanol/ethanol/water $(86: 10: 4$, by vol.) as the mobile phase, the solution was pumped through the column at a flow rate of $1.5 \mathrm{ml} \mathrm{min}^{-1}$. Ergosterol and 7-dehydrocholesterol were monitored for absorbance at $280 \mathrm{~nm}$.

\section{RESULTS}

\section{Effect of near-UV irradiation on membrane bound enzymes}

Near-UV irradiation caused changes in the activities of membrane-bound enzymes and in the ergosterol content of plasma membranes prepared from yeast cells (Fig. 1). Ergosterol content clearly decreased with increasing dosage, in parallel with reduction of activities of alkaline phosphatase and ATPase, which are well-known plasma-membrane-bound enzymes. The dosage-response curve for decrease in ergosterol content was very similar to that for reduction of enzyme activities. The activity of invertase in the plasma membrane preparations was reduced similarly to the above-mentioned enzymes by near-UV irradiation. Unlike membranebound ATPase, the activity of ATPase solubilized from the plasma membrane remained constant after exposure to near-UV, independent of dosage (data not shown). These results indicated that photodecomposition of ergosterol in the membrane might be closely related to reduction of activity of membrane-bound enzymes.

To examine the alteration in activity of membranebound enzymes by near-UV irradiation, we determined kinetic parameters for ATPase in the membrane exposed to various near-UV dosages. Maximum velocity of the
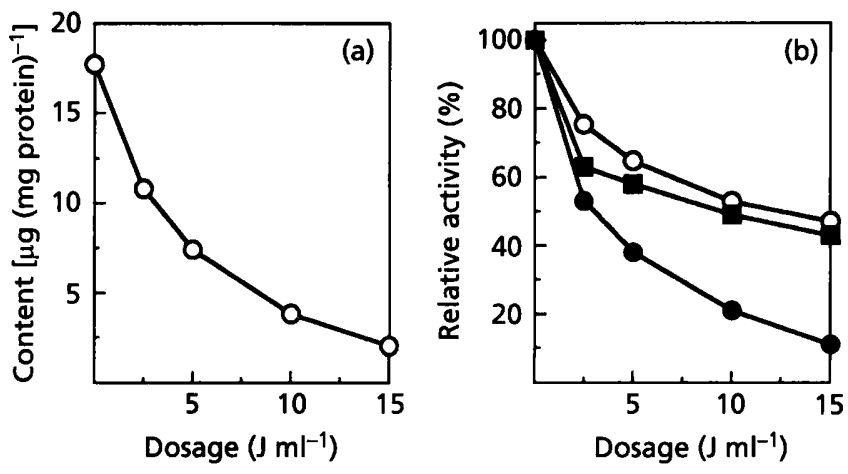

Fig. 1. Effects of near-UV irradiation on ergosterol content (a) and activity of membrane-bound enzymes (b). Plasma membranes prepared from yeast cells in the stationary phase were suspended in deionized distilled water and exposed to near-UV radiation with ice cooling and continuous stirring. Aliquots were assayed for ergosterol content or membranebound enzyme activities: alkaline phosphatase $(\square)$, invertase (O) and ATPase (O). Each value represents the mean of results from three independent experiments (SE was within $2 \%$ of the mean).

ATPase was $17 \cdot 2 \mu \mathrm{mol}(\mathrm{mg} \text { protein })^{-1} \mathrm{~min}^{-1}$ at a dosage of $0 \mathrm{~J} \mathrm{ml}^{-1}$; it decreased with increasing dosage, down to $15.6 \mu \mathrm{mol}$ (mg protein) $)^{-1} \mathrm{~min}^{-1}$ at $2.5 \mathrm{~J} \mathrm{ml}^{-1}$, and $10.0 \mu \mathrm{mol}\left(\mathrm{mg}\right.$ protein) ${ }^{-1} \mathrm{~min}^{-1}$ at $5 \mathrm{~J} \mathrm{ml}^{-1}$. On the other hand, the $K_{\mathrm{m}}$ value remained constant at approximately $23.6 \mathrm{mM}$ before and after irradiation, indicating that near-UV radiation did not affect affinity between enzyme and substrate. It was supposed from this result that reduction of ATPase activity by near-UV was caused by alteration of the conformation of the enzyme, resulting from a change in the higher-order structure of the plasma membrane through the photodecomposition of ergosterol.

\section{Dependence on oxygen for reduction of ATPase activity and ergosterol content by near-UV}

We determined in our previous study that ergosterol photodecomposition with increasing dosage of near-UV was dependent on oxygen (Arami et al., 1997). Therefore, we examined whether reduction of membranebound ATPase activity depended on the presence of oxygen. Activity of ATPase in the plasma membrane exposed to near-UV with air bubbling clearly decreased with increasing dosage, in a similar manner to that shown in Fig. 1. However, ATPase activity remained constant at $1.8 \mu \mathrm{mol}(\mathrm{mg} \text { protein })^{-1} \mathrm{~min}^{-1}$ with nitrogen gas bubbling. In the same way, the ergosterol content of the plasma membrane decreased with increasing nearUV dosage in the presence of oxygen but remained constant at $17.7 \mu \mathrm{g}$ (mg protein) ${ }^{-1}$ in the absence of oxygen. These results indicated that the reduction in activity of membrane-bound ATPase accompanying photodecomposition of ergosterol was dependent on oxygen. 

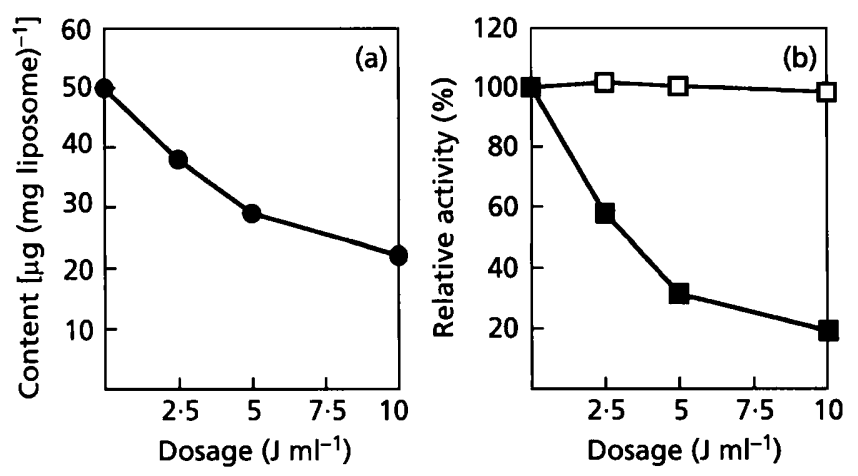

Fig. 2. Effects of near-UV irradiation on ergosterol content and ATPase activity in reconstructed liposomes. Solubilized ATPase was bound to liposomes reconstructed from total lipids of the plasma membrane. Liposomes containing ATPase were suspended in $10 \mathrm{mM}$ Tris/ $\mathrm{HCl}$ buffer $(\mathrm{pH} \mathrm{7.4)}$ containing $5 \mathrm{mM}$ $\mathrm{MgCl}_{2}$ and were exposed to near-UV radiation under the conditions shown in Fig. 1. After irradiation, liposomes were divided into two parts. One part was used for determination of ergosterol content (a) and ATPase activity (b: $\square$ ). ATPase protein was re-solubilized from the other part and its activity was determined (b: $\square$ ). Each value represents the mean of results from three independent experiments (SE was within $5 \%$ of the mean).

\section{Effect of photodecomposition of ergosterol on ATPase activity in reconstructed liposomes}

The effect of ergosterol on activity of membrane-bound enzymes was examined using liposomes prepared with ergosterol, lipids and ATPase from the plasma membrane. The normal plasma membrane is composed of many components such as proteins, lipids and various terpenoids containing photosensitizers, which can cause damage to other membrane components through generation of active oxygen. Therefore, we required exclusion of photosensitizers in these experiments. When the liposomes were exposed to near-UV radiation, photodecomposition of ergosterol and reduction of ATPase activity occurred simultaneously as in the case of the plasma membranes (Fig. 2). However, the activity of ATPase resolubilized from liposomes exposed at various dosages remained constant (Fig. 2b). These results indicated that reduction of membrane-bound ATPase activity was not directly induced by damage to the enzyme molecule, for example by destruction of peptide linkages or disulfide bonds. The reduction of ATPase activity might have occurred by alteration of the environment of the plasma membrane around the enzyme molecule.

It is well known that ergosterol plays a significant role in maintaining constant membrane function, for example membrane fluidity, the permeability barrier and the active transport system. We examined the relationship between concentration of ergosterol and ATPase activity using reconstructed liposomes. Maximum activity was seen at $5 \%$ ergosterol in liposomes (the same level as in the plasma membrane of intact cells); this activity was 2.5 times greater than for liposomes without ergosterol

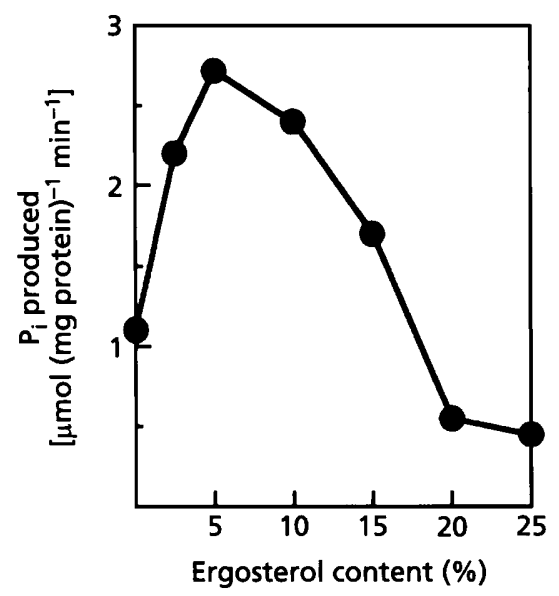

Fig. 3. Relationship between ergosterol content and ATPase activity in liposomes constructed using authentic ergosterol and two classes of lipid extracted from the plasma membrane (phospholipids and glycolipids). Each value represents the mean of results from three independent experiments (SE was within $3 \%$ of the mean).

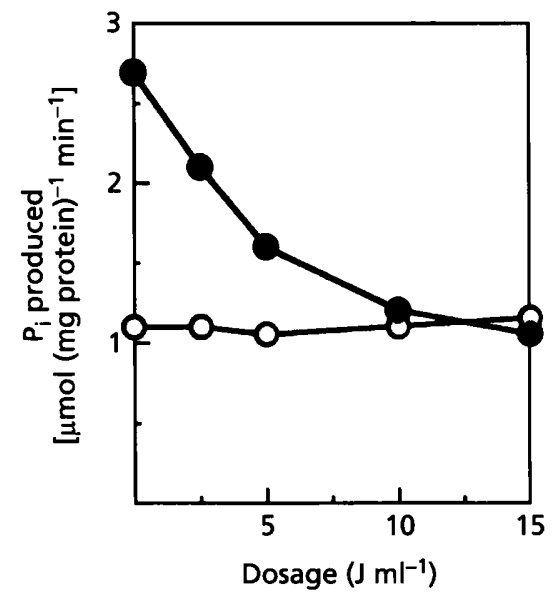

Fig. 4. Dependence on ergosterol of the decrease in ATPase activity in liposomes caused by near-UV irradiation. Two kinds of liposomes were prepared using phospholipids and glycolipids from the plasma membrane in the presence (O) and absence $(O)$ of $5 \%$ ergosterol. Both types of liposomes were suspended in the same buffer as described in Fig. 2 and were exposed to near-UV. Each value represents the mean of results from three independent experiments (SE was within $5 \%$ of the mean).

(Fig. 3). Liposomes prepared from lipids with and without $5 \%$ ergosterol were exposed to near-UV radiation. In the liposomes with ergosterol the higher activity of ATPase was markedly reduced with increasing dosage, but in the liposomes without ergosterol the lower activity remained constant (Fig. 4). These results indicated that ergosterol was essential to obtain higher activity of membrane-bound ATPase and that photodecomposition of ergosterol caused reduction of ATPase activity. 


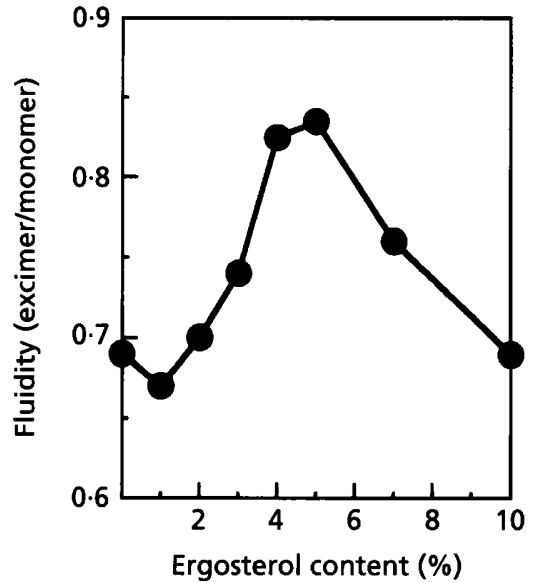

Fig. 5. Effect of ergosterol on fluidity of the lipid bilayer in reconstructed liposomes. Each value represents the mean of results from three independent experiments (SE was within $5 \%$ of the mean).

\section{Effect of near-UV irradiation on membrane fluidity in liposomes}

It is well known that sterols and lipids are one of the regulatory factors for fluidity of the lipid bilayer. We examined the relationship between fluidity and ergosterol content by using liposomes prepared with lipids extracted from the plasma membrane of yeast cells (Fig. 5). Maximum fluidity was seen at $5 \%$ ergosterol content, and it decreased with decreasing ergosterol content; this indicated that ergosterol was necessary to obtain higher fluidity of the lipid bilayer.

Liposomes prepared from lipids with and without $5 \%$ ergosterol were exposed to near-UV radiation and the fluidity of the lipid bilayer was determined (Fig. 6). The fluidity decreased with increasing dosage in liposomes with ergosterol but did not change in liposomes without ergosterol. This result indicated that fluidity of the lipid bilayer was very closely related to photodecomposition of ergosterol. The dosage-response curve for decrease in fluidity was similar to the pattern of photodecomposition of ergosterol. Similarly, when the plasma membrane was exposed to near-UV radiation, the fluidity clearly decreased with increasing dosage as mentioned above.

In non-exposed liposomes with $3 \%$ ergosterol, fluidity was slightly higher than that of liposomes without ergosterol (Fig. 5). At a dosage of $5 \mathrm{~J} \mathrm{ml}^{-1}$, however, residual ergosterol in exposed liposomes was approximately $3 \%$ but relative fluidity was $0 \cdot 48$, which was lower than the fluidity of liposomes without ergosterol (Fig. 6). It is possible that membrane fluidity is lowered by photodegradation products of ergosterol in the lipid bilayer. We reported previously that the 5,7-diene structure of ergosterol in the plasma membrane was cleaved by near-UV radiation, indicating destruction of the sterol skeleton of ergosterol (Arami et al., 1997). It

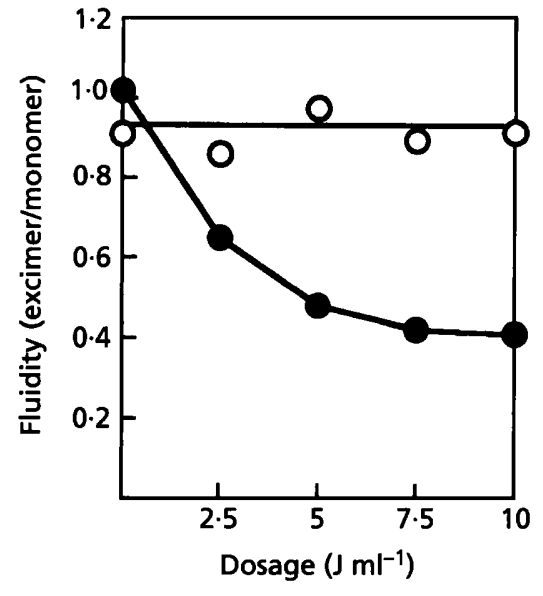

Fig. 6. Effect of near-UV irradiation on fluidity of reconstructed liposomes prepared using glycolipids and phospholipids from the plasma membrane in the presence $(O)$ and absence $(O)$ of $\mathbf{5 \%}$ ergosterol. After irradiation, both types of liposomes were labelled with pyrene dodecanoic acid and immediately assayed for fluorescence intensity. Each value represents the mean of results from three independent experiments (SE was within $5 \%$ of the mean).

has been demonstrated on the basis of data using cholesterol that sterol skeletons act as relaxants for van der Waals contact between lipid molecules. Therefore, sterol cleavage would result in enhancing of this contact, which could lead to a decrease in membrane fluidity.

\section{Effect of near-UV irradiation on the permeability barrier}

The permeability barrier of yeast cells is known to be damaged by near-UV irradiation (Arami et al., 1993; Ito $\&$ Ito, 1983). We used liposomes to examine the relationship between disruption of the permeability barrier and photodecomposition of ergosterol. The leakage of phenol red from liposomes was examined as an indication of damage to the permeability barrier by near-UV radiation. Phenol red permeates the lipid bilayer in a temperature-dependent manner, and it does not permeate below $25^{\circ} \mathrm{C}$ (Braganza et al., 1983). At this temperature the liquid phase state of the lipid bilayer is maintained. The phenol red in liposomes with ergosterol clearly leaked out with increasing near-UV dosage (Fig. 7). However, in the liposomes without ergosterol, leakage did not occur. In this experiment phenol red did not influence photodecomposition of ergosterol and was not decomposed by near-UV irradiation (data not shown).

In a series of experiments using liposomes, cholesterol was used in place of ergosterol since cholesterol is generally insensitive to near-UV radiation. Near-UV irradiation caused little or no reduction of ATPase activity, decrease in fluidity of lipid bilayer or destruction of permeability barrier in the liposomes with cholesterol. 


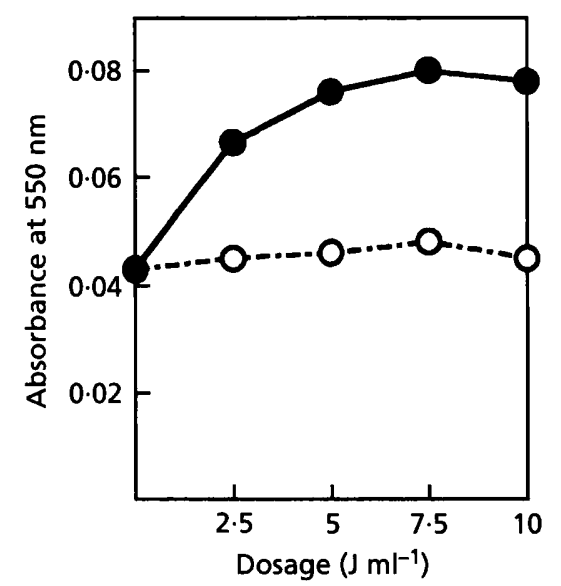

Fig. 7. Leakage of phenol red from reconstructed liposomes after near-UV irradiation. Two types of liposomes were prepared, using glycolipids and phospholipids with (O) and without ergosterol $(O)$ in $10 \mathrm{mM}$ Tris/ $\mathrm{HCl}$ buffer containing phenol red and were collected by gel filtration. After irradiation, the liposomes were removed and $A_{550}$ was measured to determine phenol red leakage. Each value represents the mean of results from three independent experiments (SE was within $5 \%$ of the mean).

\section{DISCUSSION}

Near-UV induces inactivation of $S$. cerevisiae, which, unlike the effects of far-UV, results from membrane damage rather than DNA damage (Ito \& Ito, 1983). Pyrimidine dimers were not detected under our experimental conditions, indicating lesser significance of DNA damage in inactivation of yeast cells by near-UV radiation. It has been reported that the inactivation by near-UV radiation in S. cerevisiae was caused by damage to membrane function, for example the permeability barrier (Ito \& Ito, 1983, 1984), and active transport (Arami et al., 1993). These facts indicate that the plasma membrane is a target for inactivation of the yeast cells by near-UV radiation.

It was described previously that dosage-response curves for inactivation of yeast cells by near-UV irradiation decreased sigmoidally with increasing dosage and were similar to that for decrease in active transport (Arami $e t$ al., 1993). Above a minimum level of ergosterol, yeast cells multiply normally (Leber et al., 1995). By analogy with our finding, it may also be possible to determine a range of ergosterol content at which a high level of active transport and cell multiplication are retained. However, the dosage-response curve for reduction of ATPase activity by near-UV irradiation showed no threshold and completely differed from those mentioned above. Activity of membrane-bound enzymes was very sensitive to decreased ergosterol content caused by nearUV. Therefore, it is suggested that photoinactivation of yeast cells occurs through accumulation of membrane damage such as reduction of activity of membranebound enzymes and active transport and that membrane damage can be taken as one of the fundamental factors in photoinactivation.
The function of the plasma membrane is maintained and regulated by a delicate balance of constituents in the membrane, as shown in the fluid mosaic model. Ergosterol constitutes approximately $5-7 \%$ of total lipid in the plasma membrane of the yeast cells, where it is available for regulation of fluidity and maintenance of the higher-order structure of the membrane, features which are necessary for stable maximal activity of membrane function. In practice, ergosterol was essential for stable construction of the membrane (Prasad, 1985). Needless to say, other lipids such as glycolipids and phospholipids play important roles in membrane function. Therefore, changes in membrane constituents would break down the delicate balance and eventually result in impairment of membrane function. By GLC analysis we determined that a decrease in content of unsaturated fatty acids actually occurred in several lipids of the membrane exposed to near-UV (data not shown), suggesting that peroxidative degradation of the lipids was induced by near-UV irradiation in a similar manner to that observed in previous studies using liposomal membranes (Bose et al., 1989, 1990). However, degradation of unsaturated fatty acids was slight compared with decomposition of ergosterol by near-UV irradiation. Similar results were also obtained in experiments using liposomes reconstructed with lipids extracted from membranes. Therefore, it is suggested that photodecomposition of ergosterol in the plasma membrane significantly affects the physical and chemical properties of the membrane, causing serious damage in membrane function such as lowering of the activity of membrane-bound enzymes.

Hu \& Tappel (1992) reported that UV-A light had little or no effect on activities of either glyceraldehyde-3phosphate dehydrogenase or alcohol dehydrogenase. In this study it was shown that ATPase activity did not change after near-UV irradiation of ATPase solubilized from the plasma membrane. In addition, the activities of ATPase isolated from plasma membranes or liposomes exposed to near-UV remained at normal levels irrespective of dosage. These results indicated clearly that near-UV irradiation had not damaged the primary structure of the enzyme molecule.

On the basis of these results, we suggest that reduction of ATPase activity in the plasma membrane by near-UV is not caused by the photochemical destruction of the primary structure of enzyme molecule, but is attributable to conformational changes in the membranespanning region of ATPase, caused by alteration in the higher-order structure of the plasma membrane due to photodecomposition of ergosterol. We propose that ergosterol plays an important role in photobiological responses related to membrane function of yeast cells.

\section{REFERENCES}

Allen, C. F. \& Good, P. (1971). Acyl lipids in photosynthetic systems. Methods Enzymol 123, 523-547.

Anderson, V. C. \& Thompson, D. H. (1992). Triggered release of hydrophilic agents from plasmalogen liposomes using visible light or acid. Biochim Biophys Acta 1109, 33-42. 
Arami, S., Hada, M., Itadani, A., Yamashita, S., Hachiya, K., Kanayama, M. \& Tada, M. (1993). Damage of membrane function in the yeast Saccharomyces cerevisiae by near-UV irradiation. Sci Rep Fac Agric Okayama Univ 82, 1-7.

Arami, S., Hada, M. \& Tada, M. (1997). Near-UV-induced absorbance change and photochemical decomposition of ergosterol in the plasma membrane of the yeast Saccharomyces cerevisiae. Microbiology 143, 1665-1671.

Arnezeder, C., Koliander, W. \& Hampel, W. A. (1989). Rapid determination of ergosterol in yeast cells. Anal Chim Acta 225, 129-136.

Baba, A., Lee, E., Ohta, A., Tatsuno, T. \& Iwata, H. (1981). Activation of adenylate cyclase of rat brain by lipid peroxidation. $J$ Biol Chem 256, 3679-3684.

Bose, B., Agarwal, S. \& Chatterjee, S. N. (1989). UV-A induced lipid peroxidation in liposomal membrane. Radiat Environ Biophys 28, 59-65.

Bose, B., Agarwal, S. \& Chatterjee, S. N. (1990). Membrane lipid peroxidation by near-UV: mechanism and implications. Biotechnol Appl Biochem 12, 557-561.

Braganza, L. F., Blott, B. H., Coe, T. J. \& Melville, D. (1983). Dye permeability at phase transitions in single and binary component phospholipid bilayers. Biochim Biophys Acta 731, 137-144.

Cerbon, J. \& Calderon, v. (1991). Changes of the compositional asymmetry of phospholipids associated to the increment in the membrane surface potential. Biochim Biophys Acta 1067, 139144.

Corvera, E., Mouritsen, O. G., Singer, M. A. \& Zuckermann, M. J. (1992). The permeability and the effect of acyl-chain length for phospholipid bilayers containing cholesterol: theory and experiment. Biochim Biophys Acta 1107, 261-270.

Darszon, A., Vandenberg, C. A., Schonfeld, M., Ellisman, M. H., Spitzer, N. C. \& Montal, M. (1980). Reassembly of protein-lipid complexes into large bilayer vesicles: perspective for membrane reconstitution. Proc Natl Acad Sci USA 77, 239-243.

Davis, C. B. \& Hammes, G. G. (1989). Topology of the yeast plasma membrane proton-translocating ATPase. J Biol Chem 264, 370-374.

Drissen, A. J. M., Zheng, T., In't Veld, G., Op den Kamp, J. A. F. \& Konings, W. N. (1988). Lipid requirement of the branched-chain amino acid transport system of Streptococcus cremoris. Biochemistry 27, 865-872.

Fiske, C. H. \& Subbarow, Y. (1925). The colorimetric determination of phosphorus. J Biol Chem 66, 375-400.

George, R. \& McElhaney, R. N. (1992). The effect of cholesterol and epicholesterol on the activity and temperature dependence of the purified, phospholipid-reconstituted $\left(\mathrm{Na}^{+}+\mathrm{Mg}^{2+}\right)$-ATPase from Acholeplasma laidlawii B membranes. Biochim Biophys Acta 1107, 111-118.

Hu, M.-L. \& Tappel, A. L. (1992). Potentiation of oxidative damage to proteins by ultraviolet-A and protection by antioxidants. Photochem Photobiol 56, 357-363.

In't Veld, G., Drissen, A. J. M., Op den Kamp, J. A. F. \& Konings, W. N. (1991). Hydrophobic membrane thickness and lipid- protein interactions of the leucine transport system of Lactococcus lactis. Biochim Biophys Acta 1065, 203-212.

In't Veld, G., Drissen, A. J. M. \& Konings, W. N. (1992). Effect of the unsaturation of phospholipid acyl chains on leucine transport of Lactococcus lactis and membrane permeability. Biochim Biophys Acta 1108, 31-39.

Ito, A. \& Ito, T. (1983). Possible involvement of membrane damage in the inactivation by broad-band near-UV radiation in Saccharomyces cerevisiae cells. Photochem Photobiol 37, 395-401.

Ito, T. \& Ito, A. (1984). Enhancement of porphyrin-photosensitization of yeast cells by ethanol. Photochem Photobiol $\mathbf{4 0}$, 429-434.

Kasamo, K. (1986). Purification and properties of the plasma membrane $\mathrm{H}^{+}$-translocating adenosine triphosphatase of Phaseolus mungo L. Plant Physiol 80, 818-824.

Kasamo, K. (1990). Mechanism for the activation of plasma membrane $\mathrm{H}^{+}$-ATPase from rice (Oryza sativa $\mathrm{L}$.) culture cells by molecular species of a phospholipid. Plant Physiol 93, 1049-1052.

Kasamo, K. \& Nouchi, I. (1987). The role of phospholipids in plasma membrane ATPase activity in Vigna radiata $\mathrm{L}$. (Mung bean) roots and hypocotyls. Plant Physiol 83, 323-328.

Kitagawa, S. \& Takegaki, M. (1992). Transbilayer incorporation of 1-pyrene-butyltrimethylammonium by blood platelets and its application for analyzing changes in physico-chemical properties of the membrane lipid bilayer induced by platelet activation. Biochim Biophys Acta 1107, 231-237.

Kukreja, R. C., Okabe, E., Schrier, G. M. \& Hess, M. L. (1988). Oxygen radical-mediated lipid peroxidation and inhibition of $\mathrm{Ca}^{2+}$-ATPase activity of cardiac sarcoplasmic reticulum. Arch Biochim Biophys 261, 447-457.

Leber, R., Zinser, E., Hrastnik, C., Paltauf, F. \& Daum, G. (1995). Export of steryl esters from lipid particles and release of free sterols in the yeast, Saccharomyces cerevisiae. Biochim Biophys Acta 1234, 119-126.

Marshanskii, V. K., Novgorodov, S. A. \& Yaguzhinskii, L. S. (1983). The role of lipid peroxidation in the induction of cation transport in rat liver mitochondria. The antioxidant effect of oligomycin and dicyclohexyl carbodiimide. FEBS Lett 158, 27-30.

Ohta, A., Mohri, T. \& Ohyashiki, T. (1989). Effect of peroxidation on membrane-bound $\mathrm{Ca}^{2+}$-ATPase activity of the intestinal brush-border membranes. Biochim Biophys Acta 984, 151-157.

Prasad, R. (1985). Lipids in the structure and function of yeast membrane. Adv Lipid Res 21, 187-242.

Scherer, N. M. \& Deamer, D. W. (1986). Oxidative stress impairs the function of sarcoplasmic reticulum by oxidation of sulfhydryl groups in the $\mathrm{Ca}^{2+}$-ATPase. Arch Biochem Biophys 246, 589-601.

Serrano, R., Montesinos, C. \& Sanchez, J. (1988). Lipid requirements of the plasma membrane ATPase from oat roots and yeast. Plant Sci 56, 117-122.

Singer, S. J. \& Nicolson, G. L. (1972). The fluid mosaic model of the structure of cell membranes. Science $175,720-731$.

Received 25 October 1996; revised 21 February 1997; accepted 28 February 1997. 